\title{
CULTURA ANDRÓGINA NOS FINAIS DO SÉCULO XX: REVOLUCIONANDO AS ARTES PERFORMÁTICAS BRASILEIRAS
}

\author{
Walace Rodrigues ${ }^{1}$ \\ Doutor da Universidade Federal do Tocantins - UFT \\ novowalace@hotmail.com
}

\section{INTRODUÇÃO}

A arte dos atores performáticos está ligada a várias outras formas de arte: dança, teatro, música, moda, cenografia, maquiagem, entre outras. Eles nos trazem um mundo paralelo de padrões de comportamento, questionando a ordem vigente das coisas e seus usos.

O tempo de trabalho dos artistas performáticos é um tempo circular, quase que ritual, que faz voltar em nós algo esquecido ou adormecido, que nos revolta, que nos acalma, que nos irrita, que nos acalanta. É um tempo de "comportamentos restaurados", para usar a expressão de Richard Schechner (2006).

É neste sentido que este escrito tenta trabalhar poeticamente com artistas brasileiros que souberam usar a androginia como arma discursiva e expressiva: Dzi Croquettes, Ney Matogrosso e Laura de Vison. Eles nos deixam ver que suas performances participam de um determinado submundo cultural, ativo no Brasil no final do século XX.

\footnotetext{
1 Professor doutor da Universidade Federal do Tocantins - UFT.
} 


\section{DESENVOLVIMENTO}

Para começar bem este escrito, faz-se necessário caminhar por meio de alguns conceitos algumas vezes complicados e incertos, porém esclarecedores. $\mathrm{O}$ primeiro destes conceitos é o de Cultura. Cultura é um conceito antropológico e é conhecidamente um termo difícil de ser definido, o que causa uma certa imprecisão quanto aos seus vários usos.

Conforme Roque Laraia (2003, p. 30), Edward Tylor, em 1871, foi o primeiro estudioso a tentar definir o termo cultura dentro do ponto de vista da antropologia. Tylor buscou demonstrar que cultura também pode ser objeto de estudos, pois cultura poderia ser considerada como todo comportamento aprendido.

No entanto, é o antropólogo Clifford Geertz que, na década de 1970, nos dará uma boa ideia do conceito enquanto uma teia de significações, onde todo comportamento humano é visto como ação simbólica. Portanto, é na ação social que as formas culturais encontram uma articulação precisa. Utilizo, aqui, uma passagem de Clifford Geertz (2008) sobre a importância das significações simbólicas no âmbito da cultura:

[...] nós somos animais incompletos e inacabados que nos completamos e acabamos através da cultura - não através da cultura em geral, mas através de formas altamente particulares de cultura: dobuana e javanesa, Hopi e italiana, de classe alta e classe baixa, acadêmica e comercial. A grande capacidade de aprendizagem do homem, sua plasticidade, tem sido observada muitas vezes, mas o que é ainda mais crítico é sua extrema dependência de uma espécie de aprendizado: atingir conceitos, a apreensão e aplicação de sistemas específicos de significado simbólico. (GEERTZ, 2008, p. 36).

Para o conceito de submundo cultural, arrisco a dar uma definição própria. 0 submundo cultural pode ser considerado como um mundo social "paralelo" à aquele do dito "culturalmente normal", visto por muitos como "menor", "sem valor" ou "inferior", porém constituindo uma realidade social legítima. Seus representantes estão à margem da sociedade burguesa e seguem padrões de comportamento considerados "inaceitáveis". Utilizo-me, aqui, de uma passagem do sociólogo Waldenyr Caldas (1986) sobre este ponto: 
[...] os padrões de conduta, que os antropólogos preferem chamar de padrões culturais. De início, uma questão que já se faz necessária: que padrões são esses? Trata-se de normas, regras, leis, convenções, condutas e um conjunto de valores que o indivíduo deverá respeitar e obedecer para manter o equilíbrio e o funcionamento normal da sociedade. Os padrões culturais são ainda "formas relativamente homogênicas e socialmente aceitas de pensamentos e ações, assim como objetos materiais que lhes são correlatos. Um padrão cultural resulta de interação social e exerce função de conservar uma forma de organização social. Cada sociedade ou grupo possui sanções específicas para prevenir ou punir desvios de seus padrões culturais. Os mais numerosos e funcionalmente mais importantes padrões de toda a cultura são os padrões de comportamento. Estes são representados pelos costumes e a moral, pelas leis e usos, destinados a moldar o comportamento dos indivíduos de um dado grupo social maior". (CALDAS, 1986, p. 15).

Por sua vez, a androginia pode ser vista como uma forma de apresentar-se socialmente, onde as pessoas não buscam características marcadamente femininas nem marcadamente masculinas, ou tem características consideradas do sexo oposto. Há uma "confusão" proposital entre uma aparência de homem e mulher, mesclandose os traços masculinos e femininos. Muitas vezes não conseguimos definir o sexo que tem uma pessoa andrógina somente olhando para ela. Androginia não tem nada a ver com orientação sexual, mas com formas do comportamento e aparência individual.

Nas artes, androginia pode ser vista como um artifício utilizado em apresentações performáticas para compor personagens estranhamente inusitados e absurdamente irreverentes em relação às normas socialmente aceitas. Os artistas andróginos performáticos analisados, na tentativa de questionar valores sociais tidos como "normais", reformulam as concepções de gênero vigentes, ironizando-as, jogando com elas. Nem homem, nem mulher, mas gente, um ser humano, uma pessoa, um cidadão crítico.

Também, os artistas andróginos se utilizavam, assim como os do grupo Dzi Croquettes, de uma multitude dos mecanismos de produção de discursos sobre a sexualidade. Lembro que outros artistas da época do Dzi também se utilizavam da irreverência como arma discursiva, porém não de maneira tão escrachada como o Dzi 
Croquettes. Alguns destes artistas foram: Maria Alcina, David Bowie e Mick Jagger, por exemplo.

Vale lembrar que em arte nada é gratuito, assim como nada é gratuito no uso da androginia enquanto material artístico. Muito pelo contrário, de uma forma de uso da androginia surgem outras mais instigantes, mais irreverentes, mais críticas, como aconteceu no Brasil.

Foi no começo da década de 1970 que surgiu o grupo dos Dzi Croquettes. O grupo era composto por 13 atores/dançarinos que se utilizavam de performances irônicas e inteligentes para compor seus espetáculos. Foram liderados pelo bailarino norte-americano Lennie Dale e pelo humorista e músico brasileiro Wagner Ribeiro. O grupo era visto como um dos símbolos da contracultura da época, pois traziam em suas performances uma afrogenia que contestava os costumes sérios da ditadura militar que governa o país. De sapatos de salto alto, roupas femininas, maquiagem irreverente e brilhosa, barbas e pernas cabeludas, o grupo marcou a cena teatral brasileira e parisiense. Vistos como um grupo que questionava a dura realidade vivida no Brasil governado pelos militares, acabaram quebrando tabus morais e artísticos da época. Muitos eram assumidamente homossexuais e criaram um linguajar próprio ainda hoje utilizado no mundo gay brasileiro.

Para os artistas do Dzi Croquettes que se utilizam da androginia não importava ser homem ou mulher, mas gente, gente que pensava em um regime repressivo. A androginia jogava com os papéis de gênero ${ }^{1}$ que estavam marcadamente situados nas mentes e calcados em nossa culturas brasileira da época, fazendo com que os espetáculos do Dzi Croquettes fossem censurados várias vezes. Os censores não conseguiam compreender um espetáculo tão fora dos padrões de tudo. A androginia marcava, então, sua presença nas artes performáticas brasileiras.

Porém, apesar de toda a censura às criações artísticas e críticas, elas não deixam de existir e resistiram firmemente os ataques dos censores. Roberto Schwarz (1978) analisa esta questão de outra maneira, como sendo o período de grande

1 Vale lembrar que os papeis de cada gênero para determinado grupo são construíções sociais. 
engajamento político dos artistas e intelectuais à esquerda e de grande criação cultural: [...] para surpresa de todos, a presença cultural da esquerda não foi liquidada naquela data, e mais, de lá para cá não parou de crescer. A sua produção é de qualidade notável nalguns campos, e é dominante. Apesar da ditadura da direita há relativa hegemonia cultural da esquerda no país. (SCHWARZ, 1978, 62).

O Dzi Croquettes, com movimentos de dança extremamente bem executados, com uma teatralidade irônica muito inusitada, com suas roupas femininas, com seus corpos exuberantes e com seus corpos cabeludos, causaram uma revolução de comportamento, uma liberação de valores com relação aos padrões de masculinidade e de feminilidade normatizadas como "normais" e "aceitáveis" pela sociedade vigente da época.

Ainda, vale lembrar que os espetáculos do grupo Dzi Croquettes podem ser analisados e reconhecidos como performances artísticas. Para esclarecer que performances também existem em nossas vidas, tanto que arte e vida se misturam, utilizo uma passagem de Richard Schechner (2006):

Performances marcam identidades, dobram o tempo, remodulam e adornam o corpo, e contam estórias. Performances - de arte, rituais, ou da vida cotidiana - são "comportamentos restaurados", "comportamentos duas vezes experienciados", ações realizadas para as quais as pessoas treinam e ensaiam. Assim, fica claro que, para realizar arte, isto envolve treino e ensaio. Mas a vida cotidiana também envolve anos de treino e de prática, de aprender determinadas porções de comportamentos culturais, de ajustar e atuar os papéis da vida de alguém em relação às circunstâncias sociais e pessoais. (SCHECHNER, 2006, p. 28-29).

Apesar de todo o alvoroço cultural causado pelas irreverentes apresentações do grupo Dzi Croquettes, a pesquisadora Talitta Tatiane Martins Freitas (2013) nos mostra que eles sempre foram pouco lembrados na história do teatro e das artes visuais brasileiras:

Apesar de todo sucesso nacional e internacional, pouco se escreveu sobre os Dzi Croquettes. Na verdade, o grupo aparece vez ou outra em bibliografias que versam sobre homossexualidade no Brasil, geralmente como representantes de um ainda insipiente Movimento Homossexual Brasileiro, 
que se consolidaria apenas no final dos anos 1970. No que diz respeito especificamente ao campo historiográfico, observa-se a existência de uma grande lacuna: não há registros sobre o grupo seja na área teatral, seja no campo da dança. O "resgate" é feito a partir da produção do Documentário Dzi Croquettes (2009), idealizado por Tatiana Issa e Raphael Alvarez a partir de depoimentos de atores, bailarinos, cantores, diretores que acompanharam de perto a trajetória do grupo homônimo. Além desses, são utilizadas entrevistas dos integrantes remanescentes, bem como imagens e filmagens do grupo durante uma turnê feita pela Europa entre os anos de 1974 e 1975. (FREITAS, 2013, p. 2).

Com o uso de uma gesticulação expansiva, de músicas cantadas ao vivo com vozes femininamente deformadas, de uma sensibilidade artística única e de uma poética de "palhaços" do brilho e da purpurina, o grupo Dzi Croquettes marcou definitivamente uma época de criação estética e irreverência crítica no Brasil.

Também, indo pelo mesmo caminho e influenciado pelo grupo Dzi Croquettes, o cantor Ney Matogrosso, integrante do grupo Secos \& Molhados, também artisticamente ativo a partir dos começos da década de 1970, utilizava-se para compor seu personagem artístico de cantor os seguintes elementos: pintura facial em preto e branco tal como uma máscara, corpo exoticamente exposto, um rebolado provocante, adereços de braços (pulseiras e braceletes) e pescoço, brincos, penas e panos como enfeites de cabeça e uma poderosa voz.

Em entrevista ao repórter Leonardo Lichote (2014) da revista Azul Magazine, Ney Matogrosso relata o difícil trabalho de lidar com a censura militar e de explicar seu personagem andrógino artístico:

Os primeiros passos de sua carreira, com a androginia-alienígena-tropical dos Secos \& Molhados, deram-se também sob o signo do enfrentamento. Primeiro, contra a moral da sociedade. "Quando via alguém chocado, aquilo me motivava a fazer mais. Pensava: 'Espera que você ficar chocado é agora'." Depois, num outro nível, com o próprio governo autoritário. Na primeira vez em que a banda foi convidada para aparecer na TV, a censura implicou com a maquiagem antes que eles entrassem em cena. "Diziam que era coisa de mulher. Respondi que nunca tinha visto uma maquiada daquela forma, com o nariz todo pintado de preto até a testa." Em seguida, quiseram vetar por causa do rabo de cavalo que Ney usava. Ele conseguiu convencê-los de que era um adereço artístico que não carregava agressividade em si. Reclamaram do requebrado, o cantor sugeriu que só o mostrassem na hora em que não estivesse requebrando. "Até que o censor falou: 'E esse olhar?'."(LICHOTE, 2014, p. 101-2). 
A partir da passagem anterior podemos ver como, na prática, funcionava a censura contra os artistas e seus trabalhos e com que "armadilhas" e mecanismos trabalhavam tais artistas. Ney Matogrosso nos revela que o "choque" comportamental era uma de suas armas motivacionais, assim como a maquiagem, o penteado, 0 rebolado e o olhar. Enfim, seu corpo era como um laboratório artístico que o empurrava a cantar, que dava apoio cênico e o mascarava contra os rígidos padrões morais vigentes.

Na mesma linha do antropólogo Clifford Geertz, o intelectual brasileiro Décio Pignatari (1997) nos coloca o artista como pessoas extremamente sensíveis aos significados correntes em sua sociedade, rearranjador um (des)organizador de signos diferentes. O artista do século XX sabia da força significativa da materialidade da substância de seu trabalho artístico e a usava em seu benefício. Coloco, aqui, a passagem de Pignatari: "O que me faz pensar, vaga e especulativamente, na função que ainda caberia ao artista numa sociedade programada, pois o artista é aquele que estuda os fenômenos justamente deixando-se contaminar por eles. São signoscobaia". (PIGNATARI, 1997, p. 94-95).

Também, outro grande artista andrógino foi o ator transformista Laura de Vison (Norberto Chucri David, 1939-2007). Ele ficou famoso por seus shows no Cabaré Boêmio, no bairro do Centro, no Rio de Janeiro, durante as décadas de 1980 e 1990. Suas performances destoavam dos denominados "Shows de Travestis", pois eram extremamente irreverentes. Em tais shows de travestis os artistas buscavam vestir-se como mulher, comportar-se como mulher e imitarem os trejeitos da cantora original das músicas. Por outro lado, Laura utilizava-se do escracho, de uma ironia marcadamente gay, para brincar com o público e cometer atos esdrúxulos como comer pedaços de carne crua em cena. Suas apresentações ocorriam das sextas-ferias aos domingos neste cabaré, que, durante o dia, era um restaurante vegetariano.

Em seus shows ela utiliza-se de uma maquiagem de base branca e que marcava a área dos olhos com purpurina, batons vermelhos e roupas femininas. Durante o dia, como professor de história, usava sempre um terno de cor escura. Laura ficou 
conhecida nacionalmente depois que ganhou o prêmio de melhor ator no Festival de Brasília, em 1989, por sua participação no curta metragem "Mamãe parabólica", dirigido por Ricardo Favilla e realizado por um grupo de alunos de cinema da Universidade Federal Fluminense (UFF). Em 1991 ganhou outro importante prêmio como ator: a medalha de ouro no Festival de Curta-metragem de Bruxelas, na Bélgica. Atuou em filmes, participou de séries de TV e fez peças de teatro.

Podemos verificar que todos estes artistas estavam imbuídos e foram inspirados no momento artístico da década de 1970, momento de fértil criação cultural no Brasil, como nos informou Roberto Schwarz (1978). Neste período o corpo do artista servia de sujeito e de objeto da ação artística. Nomes de artistas brasileiros como Hélio Oiticica, Lygia Clark, Lygia Pape, Artur Barrio e Cildo Meireles também beberam desta água criativa da década de 1970. Um outro grande artista a mostrar bem este uso do próprio corpo como lugar privilegiado de pensar e fazer arte foi o norte-americano Bruce Nauman. Uso-me aqui de uma passagem de Ligia Canongia (2005) sobre este mecanismo de fazer artístico:

\begin{abstract}
Bruce Nauman retira de cena o eu identificado com a noção de persona, para transformar a imagem em puro fenômeno visual, racional, fora das relações existenciais. Próximo, portanto, da estética pop e dos filmes de Warhol, Nauman, no entanto, interessa-se pela linguagem, pelos sons (naturais ou artificiais), pelos gestos físicos e outras extensões corporais, como experiências fenomenológicas essenciais para a comunicação objetiva com o mundo. Ele descarta o "eu físico" como manifestação de egocentrismo, mas afirma esse corpo como forma de intercâmbio dialético com o universo que habita. O corpo do artista - sujeito e objeto da ação - passa a ser, nesse momento, uma especie de protótipo, de molde, para a relação homemespaço. (CANONGIA, 2005, p. 81).
\end{abstract}

E é exatamente com seus próprios corpos exageradamente ornamentados, com suas roupas de gêneros opostos e com gestos físicos dúbios que os artistas analisados se colocavam na cena artística brasileira. Não havia, para eles, uma separação entre dança, canto, representação, mímica, pantomima e outras formas de arte, mas uma junção de tudo que pudesse servir a seus propósitos criadores. 
Dando um exemplo fora da cena brasileira, mas na mesma linha de pensamento sobre androginia, é, atualmente, a cantora Madonna que nos brinda com cenas andróginas interessantes, como no caso dos dançarinos no videoclipe de sua música "Girl gone wild", de 2012. Seus dançarinos vestem, neste vídeo, meias calças pretas, calçam sapatos de salto alto e seguem passos coreográficos extremamente femininos. Esses dançarinos são um exemplo caro de uso da androginia em arte, demonstrando que ela ainda é bastante utilizada como arma discursiva contra padrões de comportamento ditos "normais". É conhecido que Madonna sempre se utilizou dos discursos das minorias residentes nos EUA para compor suas canções e fazer seus vídeos, dando visibilidade a esses grupos minoritários e às criações culturais destes grupos.

Através de vestimentas dúbias em relação à definição de gênero, com o uso de roupas marcadamente reveladores e provocadoras, e deixando ver muitas partes de seus corpos, vários artistas ainda se utilizam da androginia como forma de confundir, de deixar dúvidas e de questionar os papéis sociais de gênero e tudo que os acompanha socialmente.

Uma outra das artimanhas das manifestações do submundo cultural é contestar certas ordenações e papéis sociais através da nudez corporal, de parte do corpo, geralmente. Para o estudioso da performance artística Richard Schechner (2006), a nudez pode ser "chocante" em determinadas situações, assim como o foi nas primeiras performances:

[...] a nudez causou uma excitação nas artes performáticas durante os anos 60 e começo dos 70. Mas qual a razão do choque? Nu artístico já era lugar comum na pintura e na escultura. E na outra ponta da dicotomia "alta arte $\mathrm{X}$ baixa arte", o striptease era algo bem comum - e erótico. Mas o nu artístico da arte nos museus era representação que, presumia-se, não deveria ser erótica; e o striptease estava segregado e destinado a um gênero especificamente: strippers mulheres, espectadores homens. A "nudez completa e frontal" em produções como Dionísio em 69 (68) e Oh! Calcutta (72) causaram um susto porque os atores de ambos os sexos estavam despidos em um lugar da alta arte e da performance ao vivo, e estas eram algumas vezes eróticas. Este tipo de nudez era diferente dos corpos desnudos em casa ou das duchas nos chuveiros esportivos. Em princípio, este tipo de arte não podia ser confortavelmente categorizado ou "alocado". Mas 
não levou muito tempo até que os atores nus da alta arte fossem acomodados em muitos lugares e gêneros, no ballet da Broadway, nos teatros das universidades, e nas lojas em frente. Até mesmo a pornografia chegou às vias principais, principalmente desfocando os limites entre os gêneros (SCHECHNER, 2006, p. 35).

Além da ironia, da teatralidade cênica, da nudez, das vestimentas, entre outros pontos, os artistas do submundo cultural andrógino que gozam(vam) de alguma (como o caso de Laura de Vison ou Dzi Croquettes) ou muita visibilidade (como o caso de Ney Matogrosso) se utilizaram de um estética relacionada à intenção de comoção do estilo kitsch para a criação de seus personagens e performances. Décio Pignatari (1997) nos diz que o kitsch é uma vanguarda de choque, que lida com o consumo de massa e um sentimentalismo ligado a este consumo. Uso, aqui, uma passagem deste autor sobre como surge o termo kitsch e sua abrangência nas artes:

\footnotetext{
Mais do que típico, o kitsch é um fenômeno protótipo do consumo. Consta que se trata de uma corruptela de sketch, nascida nos anos imediatos à Primeira Guerra Mundial, para designar os cartões-postais "típicos", que pintores e desenhistas alemães executavam para os soldados ingleses e americanos desmobilizados. Daí a designar outros "corruptelas" artísticas, foi um passo: oleografias sagradas ou profanas, bibelôs e estatuetas reproduzindo obras consagradas, bem como toda a estatuária acadêmica que visasse a comover, de acordo com um código sentimental já estratificado. A chamada arte tumular (que alguns espíritos ferinos, hoje, pretendem extensiva à arte em geral...), a maioria dos monumentos públicos, os santos e "santinhos" das igrejas do século passado [XIX] (e deste) podem ser enquadrados nessa categoria. Por analogia, o rótulo se estendeu a outras faixas: literatura, música, arquitetura, teatro, dança, desenho industrial, imprensa, rádio, cinema, televisão. (PIGNATARI, 1997, p. 97).
}

Assim, esta estética do kitsch pode ser vista, também, nas performances dos artistas andróginos mencionados. Neste sentido, a arte destes "brincalhões" estava extremamente envolvida com o mundo do consumo e dos padrões de comportamento trazidos por este mundo consumista de finais do século XX. 


\title{
CONSIDERAÇÕES FINAIS
}

É importante considerar que os artistas apresentados anteriormente desafiaram as barreiras artísticas, políticas e sociais de sua época com o intuito de instigar novas possibilidades, novas formas e sentidos para uma arte crítica. Eles instauraram novas possibilidades de utilização do corpo como objeto para fazer arte e intensificar as significações da vida através da manipulação de construções simbólicas de padrões sociais. Eles instauraram possibilidades poéticas para o ser humano sem a necessidade de se fechar dentro de papéis sociais de gênero pré-definidos.

Nas palavras da artista plástica Fayga Ostrower (1997) a criação artística "todo construir é um destruir". Portanto, sem subverter os padrões sociais da época, os artistas mencionados jamais conseguiriam criar uma obra de valor verdadeiramente artístico. Nesse contexto, a androginia se coloca como material de construção performática. Coloco, aqui, uma passagem de Ostrower sobre este ponto:

\begin{abstract}
Em cada função criativa sedimentam-se certas possibilidades; ao que se discriminarem, concretizam-se. As possibilidades, virtualidades talvez, se tornam reais. Com isso excluem outras - muitas outras - que até então, e hipoteticamente, também existiam. Temos de levar em conta que uma realidade configurada exclui outras realidades, pelo menos em tempos e nível idênticos. É nesse sentido, mas só e unicamente nesse, que, no formar, todo construir é um destruir. Tudo o que num dado momento se ordena, afasta por aquele momento o resto do acontecer. É um aspecto inevitável que acompanha o criar e, apesar de seu caráter delimitador, não deveríamos ter dificuldades em apreciar suas qualificações dinâmicas. (OSTROWER, 1997, p. 26).
\end{abstract}

E é exatamente esta cultura artística de submundo, de contracultura, tenta fazer: dinamizar o que está parado, criticar o que é rigidamente definido e questionar o que é tido como socialmente "certo". Para tanto, estes artistas performáticos citados armavam suas teias poéticas com "materiais" compositivos, tais como a androginia, a nudez, a ironia, o escracho, a estética kitsch, entre outros. 
Pudemos, portanto, verificar que os artistas analisados utilizavam-se da linguagem corporal como meio de "interação" social, questionando normas e padrões sociais de gênero. Além disto, temos que reconhecer o valor da diversidade artística e das inter-relações de elementos compositivos que se apresentavam nas manifestações performáticas andróginas. E por último, pudemos verificar as estratégias empregadas para o contato com o público, tais como a intimidação, provocação, aberração, sedução, comoção, entre outras. Portanto, pudemos verificar que as estratégias artísticas utilizadas pelos performáticos andróginos ajudaram na formação de uma identidade específica, própria deles e riquíssima em fruição estética na cena artística brasileira dos fins do século XX.

\section{REFERÊNCIAS BIBLIOGRÁFICAS}

CALDAS, Waldenyr. Cultura. São Paulo: Global, 1986, Col. Para Entender: 5.

CANONGIA, Ligia. O legado dos anos 60 e 70. Rio de Janeiro: Jorge Zahar Editor Ltda, 2005.

FREITAS, Talitta Tatiane Martins. "Nem dama, nem valete eu sou um Dzi Croquette": Novas sensibilidades políticas e culturais no Brasil da década de 1970. IN: Anais do XXVII Simpósio Nacional de História. Natal - RN, 2013, pág. 1-8.

GEERTZ, Clifford. A interpretação das culturas. 1a ed. 13a reimpr. Rio de Janeiro: LTC, 2008.

LARAIA, Roque de Barros. Cultura: um conceito antropológico. 16a ed. Rio de Janeiro: Jorge Zahar Editor, 2003. 
LICHOTE, Leonardo. O senhor do tempo. IN: Azul magazine. Entrevista com Ney Matogrosso. Janeiro 2014, pág. 98-103.

OSTROWER, Fayga. Criatividade e processos de criação. 6a ed. Petrópolis: Vozes, 1997.

PIGNATARI, Décio. Informação Linguagem Comunicação. 19a ed. São Paulo: Editora Cultrix, 1997.

SCHECHNER, Richard. O que é performance?. IN: Performance studies: an introduccion. 2ª ed. New York \& London: Routledge, 2006, pág. 28-51.

SCHWARZ, Roberto. O pai de família e outros estudos. Rio de Janeiro: Paz e Terra, 1978, artigo Cultura e Política, 1964-1969, pág. 61-92.

\section{REFERÊNCIAS IMAGÉTICAS}

Documento Especial - Delírio na Madrugada. Disponível em: http://www.youtube.com/watch?v=cRzvoll7nQU

Dzi Croquettes. Documentário de Tatiana Issa e Raphael Alvarez. Produção: TRIA Productions, Canal $\quad$ Brasil, $2009 . \quad$ Disponível em: http://www.youtube.com/watch?v=rgy8fXEqw98

Secos e Molhados - Sangue latino e $O$ Vira. Disponível em: 
http://www.youtube.com/watch?v=SIpErOoYJgY 